\title{
Effects of an IPad-Based Collaborative Instruction on First Graders At- Risk for Reading Delays
}

\author{
Shameka N. Johnson ${ }^{1}$ and Priti Haria ${ }^{2}$ \\ Howard University, Washington, D.C ${ }^{1}$ \\ Richard Stockton College, Galloway, $N^{2}$
}

\begin{abstract}
The current study investigates the effects of the use of an IPad-based collaborative instructional method on six first graders identified as at-risk for reading delays. The collaborative instructional method was implemented by six educators and communication disorders graduate students randomly assigned into three dyads in two phases. Phase one of the instructional method focused on training the dyads on the instructional methods; while phase two focused on implementing the instructional method on first-graders identified as atrisk for reading delays. The researchers collected and analyzed the means for pre and post student data on the Profile of Phonological Awareness. The results of the study indicate that the use of an IPadbased collaborative instructional method can yield positive results and noted improvement for students at risk for or experiencing reading delays.
\end{abstract}

\section{Introduction}

Demands of students mastering the skill of reading by third grade has compelled teachers to use evidence-based effective and comprehensive instructional practices to support the needs of all students in the classroom [1]. Common Core State Standards has also outlined for each grade level, the minimum foundational reading requirements that students must meet in order to successfully graduate to next level. These foundational requirements for first graders includes the ability to distinguish long from short vowel sounds in spoken single syllable words and blending and segmenting individual sounds. By the completion of kindergarten, the child should have mastered the ability to recognize and produce rhyming words and count-pronounce-blend and segment single syllables in spoken words [2]. Along with these demands, there has been cut back in resources and services. The classroom sizes and caseloads for SLP have increased dramaticallythus, it has become difficult for teachers and SLP to effectively enhance at-risk students' foundational reading skills. This raises the question, how can we effectively approach functionally and consistently addressing the needs of students' at risk for or experiencing reading delays?

One method to addressing this question involves the implementation of professional collaborative models for reading instruction. More specifically, reading instruction from a collaborative approach that includes both the teacher and speech-language pathologist may be beneficial.

According to the American Speech-HearingLanguage Association (ASHA) and Council of Exceptional Children (CEC), teachers and SpeechLanguage Pathologists (SLP) are encouraged to collaborate during planning and service delivery phases to provide comprehensive, rich and novel experiences to students with communication and learning difficulties, including reading delays [3] [4] [5].

Therefore, it is of importance to provide training and professional development opportunities to foster these collaborations. Research demonstrates that when strategic training programs are combined with collaborative approaches among teachers and speech-language pathologists, the overall results can benefit the professionals and the school-age child [6].

Despite understanding and knowing the importance of collaboration as an essential element to teaching, current research in this area reveals a scarcity in collaborative training opportunities. In a study of both special and general educators who graduated within the past five years, the researcher found that only $53 \%$ of special education professionals and $29 \%$ of general education teachers surveyed had received professional development that included content on collaborating with their special or general education colleagues [7]. Moreover, the inclusion of technology into a professional collaborative classroom setting can further enhance the academic abilities of the students within the class. More specifically, the implementation of collaborative approaches utilizing technology based instruction (TBI) targeting reading skills development can contribute to increased and successful reading skills and abilities in school-age children [8]. With these skills, teacher and related service provider collaborations (i.e. speechpathologists) have the capacity to assist a school in developing the potential to improve the conditions of 
learning for all students, including those experiencing reading delays.

The purpose of this project is two-fold: a) to provide collaborative technology based instructional training for teachers and communication disorders graduate student participants who are addressing common goals of children at-risk for or experiencing reading delays; b) to determine the effects of a collaborative technology based instructional approach on children at-risk for or experiencing reading skill delays.

\section{Research Method}

This study was an exploratory pilot study used to determine the effects of an IPad collaborative instruction using a pretest-posttest design. The participants included three general education (GE) teachers from a New Jersey charter school and three communication disorders graduate (CDG) students who were randomly assigned to three dyads (See Table 1). As well as the dyads, this study also included six first graders at-risk for reading delays.

Table 1. Selection Criteria for Dyads

\begin{tabular}{|l|}
\hline \multicolumn{2}{|c|}{ CDG Students } \\
\hline 1. \\
Students must be \\
able to enroll in \\
practicum or zero \\
credit independent \\
study \\
2. Students must have \\
minimum of 3.3 \\
GPA
\end{tabular}

3. Students must be able to commit to one semester of study participation

4. Students must demonstrate basic understanding of $\mathrm{PA}$ and reading skills to be determined by completion of one or more of the following courses with B or better (phonology

disorders, introduction to phonetics and child language disorders in school-age children).

GE Teachers

1. Must be employed as a teacher at GCCS

2. Must be able to attend all eight IDCO-PARSI training workshops

3. Must be able to commit to one semester of study participation

4. Must have $80 \%$ contact with students at risk for reading difficulties

5. Must demonstrate basic understanding of PA and reading skills

For both the GE teachers and CDG students, the knowledge and skills taught during the IPad-based collaborative instruction must be implemented on school-age children demonstrating difficulty or atrisk signs with reading skills.

The six first graders enrolled in the study were selected based on the following criteria:

1. Children must be verbal (more than 500 age-appropriate words)

2. Children must demonstrate some decoding skills

3. Children must not present with severe articulation disorders or language disorders

4. Children must have demonstrated delays in PA and/or reading skills

5. Children must not be currently enrolled in speech therapy or reading intervention programs.

\subsection{Instrument}

The instrument used for this study was the Profile of Phonological Assessment (Pro-PA), and IPad based assessment. The Pro-PA can be used to evaluate and describe literacy development in children with reading difficulties [\# Tanya Cole, 2012-Smarty Ears]. The assessment contains six subtests. Within this study, the researchers focused on the following three subtests

1. Rhyming (identification and production)

2. Blending (syllables and sounds)

3. Segmenting (syllables and sounds)

The scores from each of the three subtests administered were coded in the following manner:

Mastery: > or $=80 \%$ accuracy

Emerging: 50-79\% accuracy

Significant Difficulties: $<50 \%$ accuracy

\subsection{Methodology and Procedures}

The research procedure was conducted in two phases. In phase one, the dyads were to attend eight Saturday sessions over the course two months beginning in spring 2014. The participants were trained by the primary investigators on the following modules: a) Intro to interdisciplinary collaborations; b) Collaboration within classroom; c) targeting and unpacking common core content standards; d) overview of phonological awareness and reading skills; e) assessment and interpretation of reading test results; f) IPad-based collaborative instruction approach. Features of the training modules included simulated case studies, modules tests, and inclass/take-home assignments. At the completion of the module trainings, the participants were allowed to advance to phase two of the study of which included the first-grade students. 
In phase two, the participants first identified students who were possibly exhibiting at-risk or delayed reading skills to be tested. Once the students were identified and consent was established, the CDG student in each dyad tested the students to determine the presence and severity of at-risk characteristics in reading skills. Students were first tested utilizing the Profile of Phonological Awareness (Pro-PA). This was recognized as the pretest. During the administering of the Pro-PA, the CDG student of the dyad focused on three subtests (pre-subtests) probing the identified student to elicit responses that would determine their skills in the area (See Table 2).

Table 2. Pro-PA Subtests Probes

\begin{tabular}{|c|c|}
\hline Subtest & Probe \\
\hline Rhyming Identification & $\begin{array}{l}\text { Do these rhymes? big- } \\
\text { pig-dig; }\end{array}$ \\
\hline Rhyming Production & $\begin{array}{l}\text { Tell me } 2 \text { words that } \\
\text { rhyme with...( rug) }\end{array}$ \\
\hline Blending Syllables & $\begin{array}{l}\text { What word am I } \\
\text { saying? dough-nut }\end{array}$ \\
\hline Blending Sounds & $\begin{array}{l}\text { What word am I } \\
\text { saying? p-o-t }\end{array}$ \\
\hline Segmenting Sounds & $\begin{array}{l}\text { Tell me all the sounds } \\
\text { in the word big }\end{array}$ \\
\hline Segmenting Syllable & $\begin{array}{l}\text { Clap out the syllables } \\
\text { in the word rabbit }\end{array}$ \\
\hline
\end{tabular}

If the tested student demonstrated emerging or significant difficulties in any of the subtests administered, they were selected to receive the IPadbased collaborative instruction. Each student identified received collaborative instruction from the dyad using specific reading skills focused IPad apps via classroom integrated lessons and activities in reading and one to one intervention. Each collaborative instruction was conducted 4 days each week for 45 minutes each. The CDG students in each dyad lead the one to one portion of the intervention for 20 minutes and the GE teacher lead the classroom integrated lessons and activities portion for 25 minutes. This phase was conducted over a period of six-eight weeks and 16 IPad-based instructional sessions per child. At the completion of the 16 IPadbased collaborative sessions, the CDG student of each dyad administered the Pro-PA. This was recognized as the post-test.

\section{Results}

To determine the effects of the IPad-based collaborative instruction, the researchers analyzed the data from three subtests within the PRoPA evaluation (rhyming, blending, and segmenting).
Secondly, the pre-and-post data collected from the three subtests of the Pro-PA were calculated to determine the mean of each subtest within and across participants. The researchers calculated the mean differences for each subtests before and after the IPad-based collaborative instruction on six first graders.

Within the pre-subtest for rhyming, no student demonstrated mastery of rhyming skills. Four of the students performed $66 \%$ below their expected ability to produce and identify rhyming words. Indicating their rhyming skills were emerging. In addition, the remaining two students' scores were below mastery level demonstrating significant difficulty with rhyming skills. From this data, it was determined that rhyming was an emerging to difficult area for all of the students with a pre-subtest rhyming mean score of $44 \%$.

Following the implementation of the collaborative IPad-based instruction, the postsubtest 1 (rhyming) demonstrated that the ability to produce and identify rhyming words was mastered by $90 \%$ of the students. The remaining student demonstrated a decrease in rhyming skills. Overall, all of the students demonstrated a post-subtest rhyming mean score of $72 \%$ (See Fig. 1).

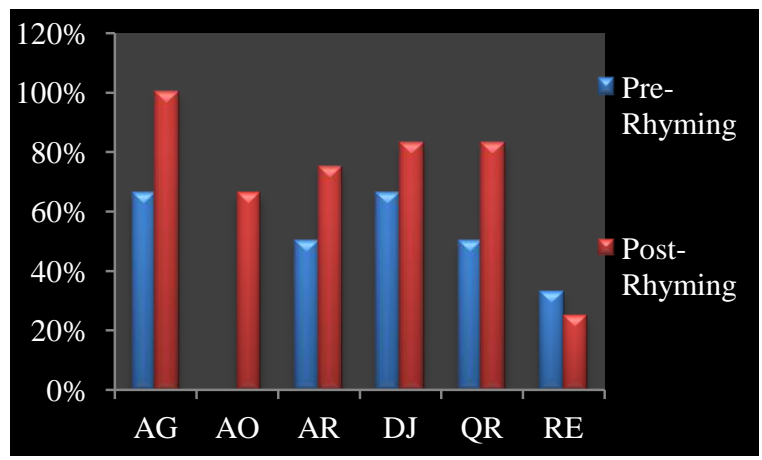

Figure. 1. Pre and post subtest 1. Rhyming scores

A closer inspection of the mean score differences between the pre and post subtest 1 (rhyming), reveals an increase of $28 \%$ in all of the students' ability to produce and identify rhyming words (see Table 3 ).

Table 3. Pre and post subtest 1 . Rhyming scores and overall mean scores

\begin{tabular}{|l|l|l|l|l|l|l|l|}
\hline Students & AG & AO & AR & DJ & QR & RE & Mean \\
\hline $\begin{array}{l}\text { Pre- } \\
\text { Rhyming }\end{array}$ & $\begin{array}{l}66 \\
\%\end{array}$ & $0 \%$ & $\begin{array}{l}50 \\
\%\end{array}$ & $\begin{array}{l}66 \\
\%\end{array}$ & $\begin{array}{l}50 \\
\%\end{array}$ & $\begin{array}{l}33 \\
\%\end{array}$ & $44 \%$ \\
\hline Post & $\begin{array}{l}100 \\
\%\end{array}$ & $\begin{array}{l}66 \\
\%\end{array}$ & $\begin{array}{l}75 \\
\%\end{array}$ & $\begin{array}{l}83 \\
\%\end{array}$ & $\begin{array}{l}83 \\
\%\end{array}$ & $\begin{array}{l}25 \\
\%\end{array}$ & $72 \%$ \\
\hline
\end{tabular}

For pre- subtest 2 (blending), the data showed that four of the students yielded performance scores of $100 \%$ on blending skills indicating mastery. Whereas, the remaining two students demonstrated emerging blending skills receiving performance 
scores of $60 \%$ and $72 \%$. From this data, it was determined that all students possessed some level of blending skills.

Following the implementation of the collaborative IPad-based instruction, the post-subtest 2 (blending) demonstrated that the ability to blend sounds into words was mastered by all of the students.

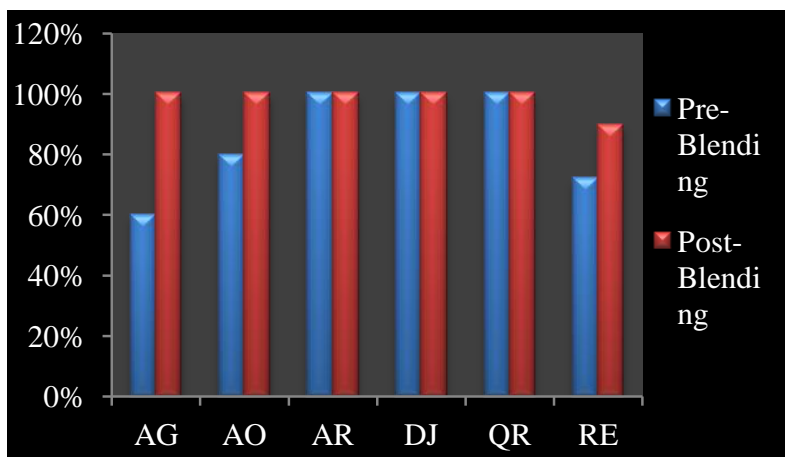

Figure. 2. Pre and post subtest 1. Rhyming Scores

A closer inspection of the mean scores differences between the pre and post subtest 2 (blending), revealed an increase of $13 \%$ in the all of the students' ability to blend sounds into words (see Table 4). In addition, analysis of the data revealed that three of the students maintained their preestablished ability to blend sounds into words post intervention.

Table 4. Pre and post subtest 2. Blending scores

\begin{tabular}{|l|l|l|l|l|l|l|l|}
\multicolumn{7}{|c|}{ and overall mean scores } \\
\hline Students & AG & AO & AR & DJ & QR & RE & Mean \\
\hline $\begin{array}{l}\text { Pre- } \\
\text { Blending }\end{array}$ & $\begin{array}{l}66 \\
\%\end{array}$ & $\begin{array}{l}80 \\
\%\end{array}$ & $\begin{array}{l}100 \\
\%\end{array}$ & $\begin{array}{l}100 \\
\%\end{array}$ & $\begin{array}{l}100 \\
\%\end{array}$ & $\begin{array}{l}72 \\
\%\end{array}$ & $85 \%$ \\
\hline $\begin{array}{l}\text { Post- } \\
\text { Blending }\end{array}$ & $\begin{array}{l}100 \\
\%\end{array}$ & $\begin{array}{l}100 \\
\%\end{array}$ & $\begin{array}{l}100 \\
\%\end{array}$ & $\begin{array}{l}100 \\
\%\end{array}$ & $\begin{array}{l}100 \\
\%\end{array}$ & $\begin{array}{l}90 \\
\%\end{array}$ & $98 \%$ \\
\hline
\end{tabular}

Data from Pre- subtest 3 (segmenting), indicated noticeable variations in the students' knowledge and skill of segmenting sounds in words. Two students demonstrated mastery in segmenting sounds in words with $83 \%$ and $100 \%$ accuracy. Three students' scores indicated emergent level skills for segmenting syllables and sounds in words with $56 \%, 72 \%$ and $61 \%$ accuracy. The remaining student yielded a score of $40 \%$ indicating significant difficulty in the ability to segment syllables and sounds in words. This student yielded a performance score of $40 \%$.

Following the implementation of the collaborative IPad-based instruction, the post-subtest 3 (segmenting) demonstrated that the ability to segment syllables and sounds in words was mastered by four of the students. The remaining two students' scores indicated segmenting skills that were emerging (See Fig. 3).

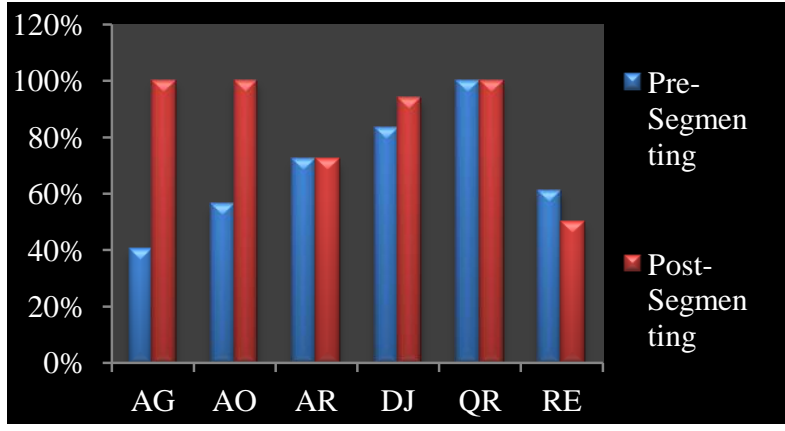

Figure. 3. Pre and Post Subtest 3. Segmenting Scores

The mean score differences between the pre and post subtest 3 (segmenting), showed an increase of $17 \%$ in three out of the six students' ability to segment syllables and sounds in words. In addition, analysis of the data revealed that two of the students maintained their pre-subtest scores and demonstrated no increase in the skill. One of the students showed a decrease in their segmenting skills (see Table 5).

Table 5. Pre and post subtest 3. Segmenting scores and overall mean scores

\begin{tabular}{|l|l|l|l|l|l|l|l|}
\hline Students & AG & AO & AR & DJ & QR & RE & Mean \\
\hline $\begin{array}{l}\text { Pre- } \\
\text { Segment } \\
\text { ing }\end{array}$ & $\begin{array}{l}40 \\
\%\end{array}$ & $\begin{array}{l}56 \\
\%\end{array}$ & $72 \%$ & $\begin{array}{l}83 \\
\%\end{array}$ & $\begin{array}{l}100 \\
\%\end{array}$ & $\begin{array}{l}61 \\
\%\end{array}$ & $85 \%$ \\
\hline $\begin{array}{l}\text { Post- } \\
\text { Segment } \\
\text { ing }\end{array}$ & $\begin{array}{l}100 \\
\%\end{array}$ & $\begin{array}{l}100 \\
\%\end{array}$ & $72 \%$ & $\begin{array}{l}94 \\
\%\end{array}$ & $\begin{array}{l}100 \\
\%\end{array}$ & $\begin{array}{l}50 \\
\%\end{array}$ & $98 \%$ \\
\hline
\end{tabular}

\section{Discussion}

Overall, $83 \%$ of students in this study demonstrated significant improvement in all areas of the reading skills components (rhyming, blending and segmenting) after the IPad-based collaborative instruction. Given the evidence, it is safe to assume that the collaborative instruction provided by the teachers and CDG dyads positively impacted students' reading skills in the areas of rhyming, blending and segmenting.

Students are expected to demonstrate mastery of rhyming, blending and segmenting skills by the end of kindergarten [\#] (Based on the New Jersey Common Core State Standards). However, the data indicates before the implementation of instruction, at least $50 \%$ of the students possessed minimal knowledge and skills for rhyming, blending and segmenting. The implementation of the IPad-based collaborative instruction resulted in an evident increase in the ability to rhyme, blend and segment for $83 \%$ of the students'. For example, AG demonstrated a significant increase of $48 \%$ in all reading skills addressed during this study. More specifically, AO initially presented with minimal knowledge and skills in the area of rhyming. Conversely, after exposure to the IPad-based 
collaborative instruction, he presented with a $66 \%$ increase in his ability to identify and produce rhyming words.

On the other hand, it is important to discuss the results of RE. During the evaluation of rhyming and segmenting skills prior to the IPad-based collaborative approach, RE demonstrated significant difficulty with rhyming and emerging skills with segmenting. Further, after exposure to the IPadbased collaborative approach, RE demonstrated a slight regression in rhyming and segmenting skills. However, he did demonstrate an increase in his blending ability resulting in a change from emerging to mastery skills. Based on reports from the dyad who provided instruction for RE, he demonstrated most difficulties when the directions necessary to retain the task appeared to be complex. This may indicate that RE was unable to attend to the task when the wording or presentation of how to complete the task was perceived to be high level. In addition, the findings may also adhere to the fact that $\mathrm{RE}$ presented with lack of motivation to complete instruction. The dyad reported that RE seemed to lose motivation and focus after 10 minutes of instruction that was too difficult. Despite, the findings of RE's results, it appears that his regression in skill was possibly due to comprehension and motivation rather than a result of the IPad-based collaborative instruction. Results from the analysis of the students' scores before and after the IPad-based collaborative instruction suggests, that training of the this instruction provided professionals with the ability to confidently collaborate, plan, implement, and assess the reading skills of children at risk for reading delays.

Ultimately, the researchers have arrived at the conclusion in this study that the IPad-based collaborative approach is a legitimate approach to addressing reading skills in students' who may be at risk or delayed. As the availability of resources becomes more limited for educators, this approach may prove to be an effective way to address the needs of students' who are at risk or experiencing reading delays without placing a financial burden on the school setting.

This study positively contributes to literature on collaboration in educational settings [9]. It provides evidence that when teachers and SLPs work as a collaborative team, benefits to the students' academic success can be achieved. It is recommended that collaboration amongst education professionals include meaningful and intensive training on how to collaborate, plan, implement instruction and intervention, interpret student assessment data and effectively share expertise to support at-risk or delayed readers. It is also recommended that the use of IPad-based instruction be encouraged in the teaching and intervention of reading skills for school-age children. Evaluating the effectiveness of these opportunities to use methods like the one applied in this study can offer possibilities to teachers and related providers of ways to enhance the production and approach of their own professional practices [9].

\section{References}

[1] National Reading Panel . (2000). Report of the National Reading Panel: Teaching children to read: In evidence-based assessment of the scientific reseearch literature on reading and its implications for reading instruction. Washington, DC : National Institute of Child Health and Human Development .

[2] Practices, National Governors Association Center for Best Practices (2010). Common Core State Standards for English/Language Arts. Washington, DC: Council of Chief State School Officers.

[3] Idol, L., Paolucci-Whitcomb, p., \& Nevin, A. (1986). Collaborative consulation. Rockville, MD : Aspen.

[4] ASHA Committee on Language Learning Disorders. (1990). A model for collaborative service delivery for students with language-learning disorders in the public schools . Rockville, MD: ASHA.

[5] Ehren, B. J. (2011, December 1). SLPs Teachers Partners Implementing Common Core Standards. Orlando, Florida.

[6] Friend, M., \& Cook, L. (2007). Interactions: Collaboration skills for school professionals, 5th ed. Boston, MA: Pearson Education Inc .

[7] Carlson, E., Brauen, M., Klein, S., Scholl, K., \& Willig, S. (2002). Study of personnel needs in special education: Key findings. Rockville, MD: Westat.

[8] Engen, L., \& Hoien, T. (2002). Phonological skills and reading comprehension. Reading and Writing: An Interdisciplinary Journal, 15, 613-631.

[9] Griffin, C. C., Jones, H. A., \& Kilgore, K. L. (2006). A qualitative study of student teachers' experience with collaborative problem solving. Teacher Education and Special Education, 29 , 44-55. 